\title{
Neuroleptic-Induced Tardive Cervical Dystonia: Clinical Series of 20 Patients
}

\author{
Clecio Godeiro-Junior, Andre C. Felício, Patrícia de Carvalho Aguiar, Vanderci \\ Borges, Sonia M. A. Silva, Henrique B. Ferraz.
}

\begin{abstract}
Background: Cervical dystonia (CD) may be classified according to the underlying cause into primary or secondary $\mathrm{CD}$. Previous exposure to neuroleptics is one of the main causes of adult-onset secondary dystonia. There are few reports that characterize the clinical features of primary CD and secondary neuroleptic-induced $\mathrm{CD}$. Herein our aim was to investigate a series of patients with neuroleptic induced tardive CD and to describe their clinical and demographic features. Patients and Methods: We retrospectively evaluated 20 patients with neuroleptic-induced tardive CD and compared clinical, demographic and therapeutic characteristics to another 77 patients with primary CD. All patients underwent Botulinum toxin type-A therapy. Results: We did not identify any relevant clinical and demographic characteristics in our group of patients that could be used to distinguish tardive and primary CD. Conclusion: Patients with tardive CD presented demographic characteristics and disease course similar to those with primary CD.
\end{abstract}

\begin{abstract}
RÉSUMÉ: Dystonie cervicale tardive induite par les neuroleptiques : série clinique de 20 patients. Contexte : La dystonie cervicale (DC) peut être classifiée en DC primaire ou secondaire, selon la cause sous-jacente. Une exposition antérieure aux neuroleptiques est l'une des causes principales de dystonie secondaire survenant à l'âge adulte. Il existe peu de comptes rendus caractérisant les manifestations cliniques de la DC primaire et de la DC secondaire induite par les neuroleptiques. Notre but était d'évaluer une série de patients présentant une DC tardive induite par les neuroleptiques et de décrire leurs caractéristiques cliniques et démographiques. Patients et méthodes : Nous avons évalué rétrospectivement 20 patients présentant une DC tardive induite par les neuroleptiques et comparé leurs caractéristiques cliniques, démographiques et thérapeutiques à celles de 77 patients atteints d'une DC primaire. Tous les patients ont été traités au moyen de la toxine botulique de type A. Résultats : Nous n'avons pas identifié de caractéristiques cliniques ou démographiques pertinentes chez notre groupe de patients qui pourraient être utilisées pour distinguer une DC tardive d'une DC primaire. Conclusion : Les patients atteints de DC tardive présentaient des caractéristiques démographiques et une évolution de la maladie qui étaient semblables à celles des patients atteints de DC primaire.
\end{abstract}

Can. J. Neurol. Sci. 2009; 36: 222-226

Cervical dystonia (CD) is the most common presentation of primary adult-onset focal dystonia ${ }^{1,2}$. Tardive dystonia, on the other hand, is a secondary movement disorder caused by exposure to dopamine-blocking medications, such as neuroleptics ${ }^{3,4}$. Craniocervical type is the most common presentation form of tardive dystonia and may be clinically identical to primary $\mathrm{CD}^{3,5,6}$. However, it has been postulated that the presence of extracervical involvement, retrocollis, and spasmodic head movements are more likely to occur in tardive $\mathrm{CD}^{7}$.

In this paper we retrospectively evaluated a series of patients with neuroleptic-induced tardive CD and described their clinical and demographic features, comparing to a control group of patients with primary $\mathrm{CD}$. Our aim was to investigate possible clinical patterns that could help to distinguish tardive and primary $\mathrm{CD}$, besides documenting exposure to dopamineblocking medications.

\section{Patients and Methods}

We retrospectively analyzed 184 medical charts of patients with $\mathrm{CD}$ who underwent Botulinum toxin type-A (BTX-A)

From the Department of Neurology and Neurosurgery, Movement Disorders Unit, Federal University of São Paulo, São Paulo, Brazil.

Received July 25, 2008. Final Revisions Submitted September 17, 2008. Correspondence to: Clecio Godeiro-Junior, Rua Dr Diogo de Faria, 650, ap. 33, Vila Clementino, Postal Code 04037-002, São Paulo, São Paulo, Brazil. 
treatment at the Movement Disorders Unit of our institution between 1990 and 2007. We excluded 66 medical charts of this review for one or more of the following reasons: still under medical investigation, did not return to re-access after BTX-A injection or incomplete data recording. Therefore, 118 were included in this analysis.

We classified patients according to the etiology of CD: primary, when there was no evidence on history, examination or laboratory investigation of any identifiable cause of the dystonia; and neuroleptic-induced tardive $\mathrm{CD}$, in accordance with criteria set out by Burke et $\mathrm{al}^{3}$ : 1- the presence of chronic dystonia; 2- a history of antipsychotic drug treatment preceding or concurrent with the onset of dystonia; 3-exclusion of known causes of secondary dystonia by appropriate clinical and laboratory evaluation; 4- a negative family history for dystonia. All patients from the latter group presented psychiatric disorders with psychotic symptoms, and that was the reason why they were using neuroleptic drugs. They all used typical neuroleptics: haloperidol or chlorpromazine.

We identified 77 patients with primary CD and 41 with secondary CD. Twenty patients from the latter group fulfilled diagnostic criteria for neuroleptic-induced tardive CD. Patients from the primary and neuroleptic-induced tardive groups were classified according to sex, age of $\mathrm{CD}$ at onset, disease duration and Tsui scale score at first medical evaluation. Details of the dystonic movement were also reviewed: torticollis, anterocollis, retrocollis, laterocollis, head tremor and pain. The medical response to BTX-A was assessed with Tsui scale ${ }^{8}$ scores at baseline and after 30-days of treatment with BTX-A. These scores were compared between groups.

The patients were also divided according to the spread of dystonia during follow-up into two groups: spreading and nonspreading $\mathrm{CD}$. We considered CD spreading when the dystonic movement extended to a different body region outside the cervical region. The pattern of progression included the following dystonic subtypes: blepharospasm, Meige syndrome, lower or upper limb dystonia, trunk dystonia, hemidystonia, multifocal or generalized dystonia.

Statistical analysis for continuous variables and comparisons between subgroups were performed by Student t-test (or MannWhitney and Wilcoxon signed rank tests, for non-parametric data); for categorical variables, comparisons between groups were performed using the Chi-square test with Yates correction. Significant values of $\mathrm{p}$ were set at $<0.05$. All statistical analyses were performed using software Prism 3.0. Parametric data is presented as mean \pm standard deviation and non-parametric data as median \pm percentile (25th and 75 th percentiles).

This protocol was submitted to and approved by the local ethical committee.

\section{RESUlts}

On Table 1 data on the psychiatric diagnosis and medication used in the group of patients with neuroleptic-induced $C D$ is shown. The mean interval for the development of $\mathrm{CD}$ after neuroleptic treatment was 22.7 months. The clinical and

Table 1: Patients with neuroleptic-induced cervical dystonia

\begin{tabular}{|c|c|c|c|c|c|c|}
\hline Case & $\begin{array}{c}\text { Onset } \\
\text { Age } \\
\text { (Years) }\end{array}$ & Sex & Psychiatric Diagnosis & $\begin{array}{l}\text { Antipsychotic } \\
\text { drugs }\end{array}$ & $\begin{array}{l}\text { Exposure Interval* } \\
\text { (months) }\end{array}$ & Spreading \\
\hline 1 & 42 & $\mathrm{M}$ & Schizophrenia & Haloperidol & 6 & No \\
\hline 2 & 74 & $\mathrm{~F}$ & Agressive behaviour & Chlorpromazine & 24 & Oromandibular \\
\hline 3 & 44 & $\mathrm{~F}$ & Acute psychosis & Haloperidol & 2 & Blepharoespasm \\
\hline 4 & 59 & M & Acute psychosis & Haloperidol & 6 & No \\
\hline 5 & 46 & $\mathrm{~F}$ & Schizophrenia & Chlorpromazine & 12 & Blepharoespasm \\
\hline 6 & 18 & M & Schizophrenia & $\begin{array}{l}\text { Chlorpromazine }+ \\
\text { Haloperidol }\end{array}$ & $<1$ & No \\
\hline 7 & 32 & M & Schizophrenia & Haloperidol & 36 & No \\
\hline 8 & 59 & $\mathrm{~F}$ & Bipolar Disorder & Haloperidol & 84 & No \\
\hline 9 & 47 & M & Acute psychosis & Haloperidol & 24 & No \\
\hline 10 & 41 & M & Schizophrenia & Haloperidol & 12 & No \\
\hline 11 & 38 & M & Bipolar Disorder & Haloperidol & 48 & No \\
\hline 12 & 34 & $\mathrm{~F}$ & Acute psychosis & Chlorpromazine & $<1$ & No \\
\hline 13 & 49 & $\mathrm{~F}$ & Depression & Chlorpromazine & 24 & Upper Limb \\
\hline 14 & 51 & M & Acute psychosis & Haloperidol & 24 & Blepharoespasm \\
\hline 15 & 42 & M & Agressive behaviour & Chlorpromazine & 60 & Trunk \\
\hline 16 & 24 & M & Schizophrenia & Haloperidol & 12 & Upper Limb \\
\hline 17 & 32 & $\mathrm{~F}$ & Acute psychosis & Haloperidol & 8 & Meige Syndrome \\
\hline 18 & 33 & M & Bipolar disorders & Chlorpromazine & 24 & No \\
\hline 19 & 32 & $\mathrm{~F}$ & Acute psychosis & Haloperidol & 36 & No \\
\hline 20 & 42 & $\mathrm{~F}$ & Acute psychosis & Haloperidol & 10 & No \\
\hline Mean & 41.9 & $55 \% M$ & & & 22.7 & \\
\hline
\end{tabular}

*Time to develop cervical dystonia after neuroleptic drug use. 
Table 2: Demographic and clinical characteristics of Tardive CD compared to Primary CD

\begin{tabular}{cccc}
\hline & Tardive CD & Primary CD & $p$ value \\
$\mathbf{N = \mathbf { 2 0 }}$ & $1: 1.2$ & $1.4: 1$ & $0.41^{\mathrm{a}}$ \\
Female: Male & $40 \pm 2.8^{*}$ & $39 \pm 1.8^{*}$ & $0.95^{\mathrm{b}}$ \\
Onset Age (years) & $27 \pm 4.3^{*}$ & $65 \pm 7.0 *$ & $0,0075^{\mathrm{b}}$ \\
Disease duration (months) & $8(40 \%)$ & $27(35.1 \%)$ & $0.88^{\mathrm{a}}$ \\
Spreading & $9(7-12.5)^{\#}$ & $9(7-11)^{\#}$ & $0.92^{\mathrm{c}}$ \\
Tsui Score & $7(35 \%)$ & $33(42.8 \%)$ & $0.70^{\mathrm{a}}$ \\
Head Tremor & $14(70 \%)$ & $56(72.7 \%)$ & $0.97^{\mathrm{a}}$ \\
Pain & $6(30 \%)$ & $16(20.8 \%)$ & $0.56^{\mathrm{a}}$ \\
Torticollis & $1(5 \%)$ & $1(1.3 \%)$ & $0.87^{\mathrm{a}}$ \\
Anterocollis & $1(5 \%)$ & 0 & $0.46^{\mathrm{a}}$ \\
Retrocollis & $4(20 \%)$ & $23(29.8 \%)$ & $0.55^{\mathrm{a}}$ \\
Torticollis + Laterocollis & $1(5 \%)$ & $6(7.8 \%)$ & $0.95^{\mathrm{a}}$ \\
Torticollis + Anterocollis & $2(10 \%)$ & $15(19.5 \%)$ & $0.50^{\mathrm{a}}$ \\
Torticollis + Retrocollis & $1(5 \%)$ & 0 & $0.46^{\mathrm{a}}$ \\
Retrocollis + Laterocollis & $2(10 \%)$ & $7(9.1 \%)$ & $0.76^{\mathrm{a}}$ \\
Torticollis + Laterocollis + Anterocollis & $2(10 \%)$ & $9(11.7 \%)$ & $0.85^{\mathrm{a}}$ \\
Torticollis + Laterocollis + Retrocollis & & & \\
\hline
\end{tabular}

* - Mean and Standard Deviation; \# - Median and Percentiles; a- Chi-square test with Yates correction; b - Student t Test; c- Mann-Whitney test. ${ }^{+}$- Disease duration before first neurological examination.

demographic characteristics of both groups (primary and tardive CD) are summarized on Table 2. Disease duration before first medical evaluation was significantly shorter in the tardive CD group $(27 \pm 4.3$ months vs. $65 \pm 7.0)$, whereas Tsui score was similar (9.7-12.5 vs. 9.7-11). The phenomenology of CD in the tardive group was indistinguishable from the primary one.

In both groups of patients with CD it was observed spreading to other body regions ( $40 \%$ in tardive group vs. $35.1 \%$ in primary one). The pattern of progression in the tardive and primary groups is presented in the Figure. Both groups had clinical follow-up during a similar period: $44.50 \pm 11.13$ months in tardive group and $48.58 \pm 4.829$ months in the primary one $(\mathrm{p}=0.16)$.

All patients were treated with BTX-A. Fifteen patients in tardive group and 43 in the primary one were treated with Dysport $^{\mathrm{R}}$ (mean dose of $550 \mathrm{UI} \pm 140$ vs. $513 \pm 140.2 ; \mathrm{p}=0.32$ ) whereas five patients in the tardive group and 34 in primary one were treated with BotoxR (mean dose of $265 \mathrm{UI} \pm 81.43$ vs. $255.3 \pm 73.5 ; \mathrm{p}=0.34)$.

We compared Tsui score at first evaluation (baseline) and 30days after BTX-A in each group: in tardive CD group, median Tsui score was 9 (7-12.5) at baseline vs. 6 (3.5-9) 30-days after BTX-A, p=0,0002; in the primary CD group was 9 (7-11) at baseline vs. 4 (2-6) 30-days after BTX-A, p <0.0001. Both groups presented a significant response to BTX-A therapy. However, if we compare Tsui score 30-days after BTX-A between tardive and primary groups, the latter presents a better response: Tsui score was 6 (3.5-9) in tardive CD group vs. 4 (2$6)$ in the primary CD group, $\mathrm{p}=0,04$.

\section{DISCUSSION}

We did not identify any relevant clinical or demographic characteristics in our group of patients that could be used to distinguish tardive and primary CD. A previous report ${ }^{5}$ observed that torticollis was present in only $34 \%$ of patients with tardive $\mathrm{CD}$, which is similar to what we found $(30 \%)$.

It has been said that when individually analyzed, retrocollis, spasmodic head movements, and extracervical involvement are predictive of tardive CD. Similarly, torticollis, laterocollis, and presence of trick maneuvers were also considered as predictors for idiopathic $\mathrm{CD}^{7,9}$. However, according to our data, the pattern of rotations did not differ between groups, as well as extracervical involvement, which occurred in both groups and did not present significant difference (40\% in Tardive CD group vs. $35.1 \%$ in Primary one, $\mathrm{p}=0.88$ ). In our study, data on sensory tricks was not regularly registered on medical charts and for this reason we did not use this information for statistical purposes.

Our study revealed that the presence of head tremor was similar in both groups (35\% in tardive group and $42.8 \%$ in primary group). This is in line with another report that showed similar results ${ }^{7}$. The presence of pain was also similar in both groups (70\% in tardive group and $72.7 \%$ in primary group). Once again, we observe that clinical differentiation is very difficult and ultimately, the definitive diagnostic of tardive CD will still depend on documentation of neuroleptic exposure as observed by Molho et $\mathrm{al}^{7}$.

Idiopathic CD presents a bimodal age distribution with an early peak in childhood with most of these cases generalized. The other peak occurs later in adulthood and most of these patients present focal-onset dystonia and rarely generalize ${ }^{5}$. A 


\section{Pattern of Spreading}

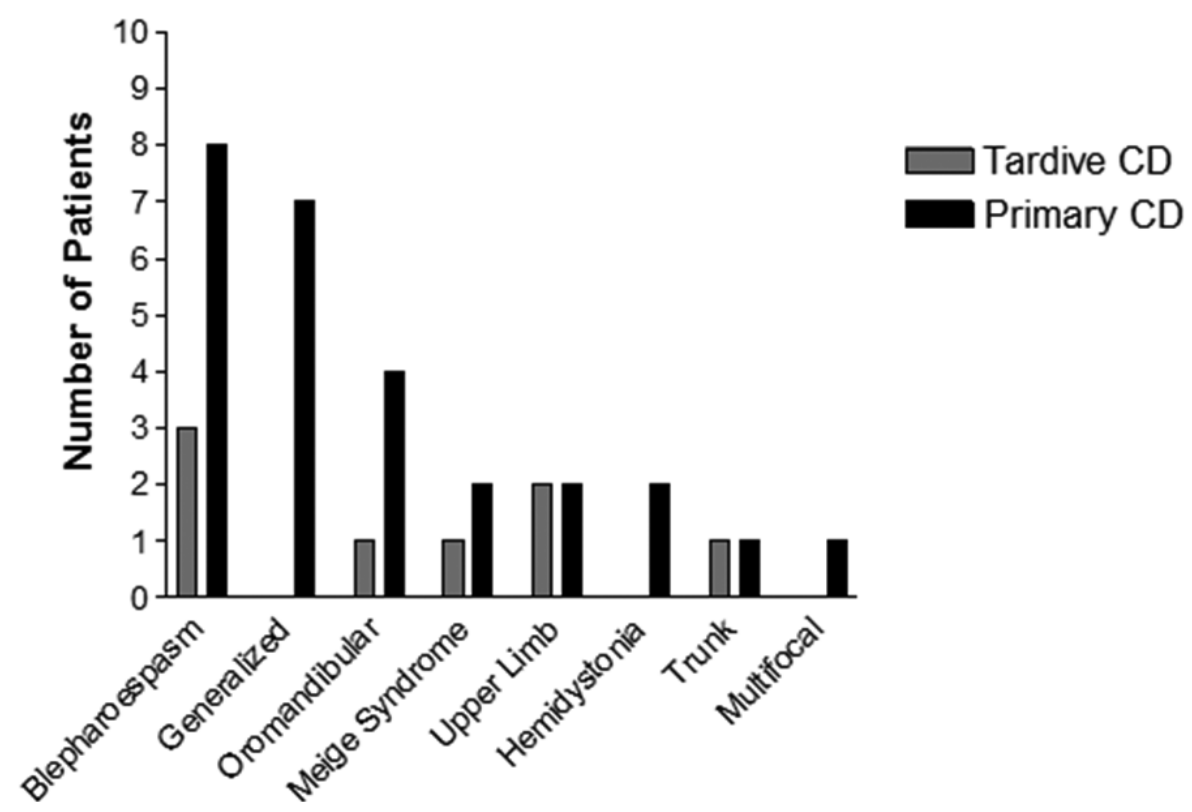

Figure: This figure shows the pattern of spreading in both groups (primary and tardive CD). Grey bars represent patients in the tardive group; black bars, primary CD group. None of the patients in the tardive group had progression to a generalized form of dystonia, hemidystonia or multifocal dystonia. The follow-up period over which time spread was noted was, respectively, $44.50 \pm 11.13$ months in tardive group and $48.58 \pm 4.829$ months in the primary one.

previous report showed that males with $\mathrm{CD}$ are younger than females at onset of symptoms, although they have similar natural history ${ }^{10}$. Brashear et al presented a group of patients with tardive $\mathrm{CD}$ younger than idiopathic $\mathrm{CD}^{11}$. However, in our study, onset age was similar in both groups $(40 \pm 2.8$ years in tardive group and $39 \pm 1.8$ in primary one) and was similiar to findings in previous reports ${ }^{7,10}$. We could not find any significant differences in sex prevalence between tardive and primary groups.

Tardive dystonia could be focal, segmental, or, less commonly generalized. At the time of maximum severity, most of patients with tardive dystonia $(72 \%)$ had segmental presentation and $13 \%$ progressed to generalized ${ }^{5}$. In our group of patients, $40 \%$ of patients had progression of their CD to other body parts, but all remained segmental. Our data shows a lower spreading rate than previous reports ${ }^{7,10}$, and we believe this is because of the shorter period of follow-up (less than five-years) in our sample and the fact that the neuroleptics were withdrawn from all patients.

In our series, disease duration before first medical evaluation was shorter in tardive CD patients than in primary ones $(27 \pm 4.3$ vs. $65 \pm 7.0$ months). We believe that is probably due the fact that patients in the first group already had physicians following the disease for which the neuroleptics were prescribed. These physicians were able to identify $\mathrm{CD}$ and request specialized evaluation earlier than that provided for the primary group, resulting in a shorter disease duration.
Treatment of neuroleptic-induced CD is very difficult sometimes demanding therapeutic associations such as atypical neuroleptics and BTX-A $\mathrm{A}^{12-14}$. Recovery is not always fullyobtained even when the causative drug is removed. A sustained recovery pattern is also difficult to obtain. Therefore, better strategies for these patients are needed. None of the patients were using neuroleptics at the time of BTX-A treatment, and their outcome was significantly different. Both groups received similar doses of BTX-A and showed favorable improvement. However, the 30-day response after BTX-A application in primary group was better than in tardive group: Tsui score $=6$ (3.5-9) in tardive group vs. 4 (2-6) in primary CD, p =0,04. We believe that, for similar doses of BTX-A, patients with tardive $\mathrm{CD}$ tend to present a worse response when compared to primary ones. A report by Brashear et al on seven patients with tardive $\mathrm{CD}$ who were treated with BTX-A showed similar results on BTX-A response when compared to primary ones. In this report, the dose of BTX-A was significantly different between groups, larger in tardive CD patients. The authors concluded that patients with tardive $\mathrm{CD}$ may require more BTX-A because of more complicated movements, larger muscles involved or more pain ${ }^{11}$.

Our study presented some limitations, especially due to its retrospective nature. Although data was based on information obtained from medical charts with the participation of different physicians throughout the period of this study, the final diagnosis, BTX-A injections, and Tsui scale scoring were always 
made concurrent with one of the authors (HBF, VB, SMAS, PMCA), and the same standard protocol was used for diagnostic purposes and treatment.

In conclusion, patients with tardive $\mathrm{CD}$ presented demographic characteristics and disease course similar to those with primary $\mathrm{CD}$. We believe the difference we found as compared to prior authors was due to a shorter disease duration (although not statistically different from the primary group) and early use of BTX-A in the tardive group possibly interfering with disease course. Further prospective studies with larger samples, longer follow-up and stricter group matching are warranted to add more information on clinical and phenomenology differences between patients with primary and tardive CD.

\section{REFERENCES}

1. Nutt JG, Muenter MD, Aranson A, Kurland LT, Melton LJ. Epidemiology of focal and generalized dystonia in Rochester Minessota. Mov Disord. 1988;3(3):188-94.

2. de Carvalho Aguiar PM, Ozelius LJ. Classification and genetics of dystonia. Lancet Neurol. 2002;1(5):316-25.

3. Burke SE, Fahn S, Jankovic J, Marsden CD, Lang AE, Gollomp S, et al. Tardive dystonia: late-onset and persistent dystonia caused by antipsychotic drugs. Neurology. 1982;32(12):1335-46.

4. Camargo CH, Teive HA, Becker N, Baran MH, Scola RH, Werneck LC. Cervical dystonia: clinical and therapeutic features in 85 patients. Arq Neuropsiquiatr. 2008;66(1):15-21.
5. Kang UJ, Burke RE, Fahn S. Natural history and treatment of tardive dystonia. Mov Disord. 1986;1(3):193-208.

6. Ferraz HB, Andrade LA. Symptomatic dystonia: clinical profile of 46 Brazilian patients. Can J Neurol Sci. 1992;19(4):504-7.

7. Molho ES, Feustel PJ, Factor SA. Clinical comparison of tardive and idiopathic cervical dystonia. Mov Disord. 1998;13(3):486-9.

8. Tsui JK, Eisen A, Stoessl AJ, Calne S, Calne DB. Double-blind study of botulinum toxin in spasmodic torticollis. Lancet. 1986; 2(8501):245-7.

9. Jahanshahi M, Marion MH, Marsden D. Natural history of adultonset idiopathic torticollis. Arch Neurol. 1990;47(5):548-52.

10. Kiriakakis V, Bhatia KP, Quinn NP, Marsden CD. The natural history of tardive dystonia. A long-term follow-up study of 107 cases. Brain. 1998;121(11):2053-66.

11. Brashear A, Ambrosius WT, Eckert GJ, Siemers ER. Comparison of treatment of tardive dystonia and idiopathic cervical dystonia with botulinum toxin type A. Mov Disord. 1998;13(1):158-61 .

12. Havaki-Kontaxaki BJ, Kontaxakis VP, Margariti MM, Paplos KG, Christodoulou GN. Treatment of severe neuroleptic-induced tardive torticollis. Ann Gen Hosp Psychiatry. 2003;2(1):9.

13. Tarsy D, Kaufman D, Sehti KD, Rivner ME, Molho E, Factor S. An open-label study of botulinum toxin A for treatment of tardive dystonia. Clin Neuropharmacol. 1997;20(1):90-3.

14. Chatterjee A, Forrest GM, Giladi N, Trosh R. Botulinum toxin in the treatment of tardive dystonia. J Clin Psychopharmacol. 1997;17(6):497-8. 